\title{
Stress Testing of Commercial Banks' Exposure to Credit Risk: A Study Based on Write-off Nonperforming Loans
}

\author{
Wei Lu ${ }^{1} \&$ Zhiwei Yang ${ }^{1}$ \\ ${ }^{1}$ School of Management, University of Science and Technology of China, Hefei, China \\ Correspondence: Zhiwei Yang, School of Management, University of Science and Technology of China, Hefei, \\ China. E-mail: yzhw@mail.ustc.edu.cn
}

Received: April 12, 2012

doi:10.5539/ass.v8n10p16
Accepted: May 16, $2012 \quad$ Published: August 1, 2012

URL: http://dx.doi.org/10.5539/ass.v8n10p16

\begin{abstract}
This study introduced a stress-testing model with a dummy variable that refers to write-off non-performing loans (NPL) by Agricultural Bank of China. A new variable Y that indicated the rate of NPL in major national commercial banks in terms of logit transformation was applied to test stress tolerance. This article built a regression model on the basis of four explanation variables: the growth rate of GDP, indicator of customer price, the growth rate of supplying nominal currency and indicator of house price. Then we took advantages of VAR model to establish the relationship between variables. Based on the model, diverse scenario was set up to conduct stress test to NPL of commercial banks. The test covered four quarters and discovered that lower growth rate of GDP, slump in CPI, slowdown in supply of nominal currency and surging price of house are in charge of short-term increase in non-performing loans. From long-term perspective, the commercial banks would initiate internal system to mitigate the shock from volatile macro factors.
\end{abstract}

Keywords: credit risk, write-off nonperforming loans (NPL), VAR model, stress-test

\section{Introduction}

Further opening of domestic financial market enables closer connection to international markets and challenges credit risk management of national commercial banks. Stress test is well known to evaluate the stability of commercial banks' credit system by stimulating potential risk exposure to extreme shock like financial crisis. The test works especially towards unexpected macro fluctuation on banking system and therefore plays a crucial role in forecasting and reducing systematic financial risk, which contributes to the stabilization financial system.

This paper applied macro stress test to the analysis of changes in NPL (nonperforming loan) of a commercial bank under given macro-economic shock. This article consists of three parts: Section one where we reviewed the national and international literatures concerning macro stress test. Section two where we stimulated a macro stress testing model in terms of NPL in Chinese commercial banks and quarterly macroeconomic data. Finally, we hypothesized certain scenario on the basis of model and then forecasted the new financial status of NPL of commercial bank in one year after extreme shocks.

\section{Literature Review}

IMF defined macro stress testing as a range of techniques used to assess the vulnerability of a financial system to 'exceptional but plausible' macroeconomic shocks. International Organization of Securities Commissions (1995) suggested that stress test analyzes the impact on portfolio of worst situation in market (rise of interest rate and crash of stock market). In 1999, IOSCO specified that stress test estimates and measures extreme but plausible risk of portfolio. Guidelines for the Stress Testing of Commercial Banks by CBRC (China Banking Regulatory Commission) indicates that The term "stress testing" as mentioned in these Guidelines refers to such a kind of risk analysis method in which the quantitative analysis method is usually adopted, the frangibility of a single bank, a bank group and the banking system is evaluated and judged through forecasting possible losses from small probability events or any other extremely unfavorable circumstances as assumed and analyzing the negative impact of such losses on the bank's profitability and capital, and necessary measures are thus taken.

Stress test can take advantage of different data sets at either portfolio or aggregate level. Aggregate-level stress test directly specifies the relationship between macro variables and banking aggregate elements and analyzes the risk exposure of a group of reporting firms under certain stress scenario. Portfolio-level stress test emphasizes on 
the banks' unique credit risk exposure to macro shock and discusses loss in each unit under exceptional circumstances. Portfolio-level stress test is more operational and includes feedback effect in financial institutions. However, the methodology requires larger sample size of historic data, while Chinese commercial bank generally lacks long-term easily-accessible and well-recorded database. Therefore, due to low availability of data, this paper decided to develop a stress test at aggregate level, which generally demands macroeconomic data of the whole financial system.

How to build credit model determines the operation of macro stress test. Framework from Wilson'and Merton's models contributes most to current theoretical research of stress-test. Wilson (1997a, 1997b) selected macro economical factors like the growth rate of GDP and interest rate as risk factors, default rates as measurement of credit assets, and then tested in terms of the relationship between macro situation and default rate. Merton's model (1947) applied market information (the stock price and bond price) to evaluate credit risk. As the market information referred to the expectation of investors, Merton's model performs more prospective than other historic-data based models. However, in reality, Wilson's model is more operational and more practical. Consequently, most of macro credit models are in favor of Wilson's Credit Portfolio View. Like Mckinsey \& Company, Singapore Ministry of Finance, Hong Kong Monetary Authority, Bank of Finland, Bank of England, most institutions applies Wilson's framework to credit risk stress test model.

Boss M (2002) developed Wilson's model by adopting aggregate-level default rates of firms to test Australian bank department and discovered that industrial production, inflation rate, stock index, nominal short-term interest rate and oil price significantly imposed on default rates of firms. Subject of Virolaninen's (2004) research was Bank of Finland. He used firm's bankruptcy data in the model concerning the relationship between macro factors and default rates. Empirical result in his paper indicated that GNP, firm's loans and interest rate significantly affected default rates. Virolaninen created a variety of scenarios to conduct stress test and explored different credit exposures of Bank of Finland to macro shocks. Jim Wong, Ka-fai Choi and Tom Fong(2008) suggested the strong relationship between the default rates of bank loans and major macroeconomic factors, like Hong Kong's GDP, interest rates and property prices and the Mainland's GDP, They set two pressure indicator to conduct testing to retail banks in Hong Kong in terms of Monte Carlo simulation. The scenario resembled Asian crisis in year 1998. Test result proved that current credit risk of banking system was moderate. Allan Kearns, Erlen - maier and Gersbach H(2004) developed macro credit equation to assess default rate of loans and then respectively applied testing to Irish retail credit institution and Norway Central Bank.

Recently, Chinese scholars increasingly took interest in the research of macro stress test. From theoretical perspective, Sun Lianyou (2007), Gao Tongyu and Chen Yuanfu (2006) reviewed related international literatures and theoretically discussed stress test in China. Xu Mingdong and Liu Xiaoxing (2008) compared several macro stress test methodologies and briefly introduced testing process as well as how the whole process guaranteed the stability of financial system. Form empirical research perspective, Li Jiang and Liu Liping (2008) regarded default rates of loans as the indicator of evaluating credit risk of banking system and selected macro economical factors that imposed on bank credit. They made use of Multi linear regression model to integrate these factors and finally generate one comprehensive macro factor. Apart from traditional macro factors, bank's degree of finance leverage was brought in by Zhou Yuan (2010) to build stress models, which targeted at commercial banks in Jiang Su province. Zhou Yuan assumed "bad" and "very bad" stress scenarios and later explored that under given "bad" stress, local banks would be in extremely hard time. Chinese scholars preferred regarding NPL as kind of element to measure pressure tolerance. But considering Chinese banks, especially Agriculture Bank of China, have removed plenty of NPL from balance, empirical research might suffer from removal of NPL, where a turning point of financial performance would exist. In order to build a more practically oriented stress-test model, further exploration is required to find out how macro shock would influence rate of NPL in commercial banks given the removal of NPL. The article improved past model by bringing in a dummy variable to represent write-off NPL. This effort would take the distraction of removed NPL away from the analysis how macro economy impacts credit risk in commercial banks.

\section{Model and Data}

This paper develops macro stress-test models by Wilson (1997a,1997b), Boss (2002) and Virolainen (2004) and creates a new conceptual model that could be applied to Chinese commercial banks. Our framework consists of two parts: one part refers to empirical model concerning credit risk of commercial bank as well as macro economical system. The other part sets up scenarios about future and uses empirical model born in part one to conduct stress test.

\subsection{Model}

Non-linear relationship between default rates and macro factors enables transformation from rate of NPL to $Y_{t}$ in terms of logit model. Equation (1) explains the logit-relationship between $Y_{t}$ as mediator variable and NPL: 


$$
Y_{t}=\ln \left(\frac{1-N P L_{t}}{N P L_{t}}\right)
$$

Where NPLt presents ratios of non-performing loans at time t, Yt is a aggregate grouping economical indicator at time t. Equation (1) implies that Yt is negatively related to NPLt. More default rates lead to less Yt With the mediator variable, we can reasonably establish stress model:

$$
\begin{gathered}
Y_{t}=m+A_{1} X_{t}+\ldots+A_{1+s} X_{t-s}+\phi_{1} Y_{t-1}+\ldots+\phi_{k} Y_{t-k}+\beta_{t} D_{t}+v_{t} \\
X_{t}=n+B_{1} X_{t-1}+\ldots+B_{p} X_{t-p}+C_{1} Y_{t}+\ldots+C_{k} Y_{t-k}+\varepsilon_{t}
\end{gathered}
$$

Where $X_{t}$ is macro economical factor, D a new dummy variable that defines the removal of NPL and is assgined 0 over the first three quarters in 2008, 1 since Q4. Association between NPL and equation (1) generates a group component of macro factors. If we put the component into equation (2), we can estimate coefficient of each macro factor and therefore the default-model. When we conduct stress testing and later assume stress scenario, we can use (3) to estimate each macro factor. Association of estimation with equation (2) leads to value of Y under given scenario. Y could be used in equation to calculate rates of NPL.

Equation (2) reflects the relationship between macro economical factors and group component. The conceptual model in this article includes the function of dummy variable D and the association of macro economical data with previous year's macro economical data with the use of lagged terms.

Equation (3) reports the interaction effect among macro economical factors. This paper mainly uses VAR model to describe how these factors are related to each other. Vector auto regression (VAR) is an econometric model used to capture the evolution and the interdependencies between multiple time series. All the variables in a VAR are treated symmetrically by including for each variable an equation explaining its evolution based on its own lags and the lags of all the other variables in the model. As for the prediction of time series of macro factors, most literatures applies auto regression (AR) model to individually predict each macro economical factor. Considering these factors are highly sensitive to the fluctuation of one factor, we should build VAR model like equation (3) to include the interdependency among factors. And the key role of commercial banks in the economy of China determines the inclusion of banking system's feedback effect on economy development. According to the underlying philosophy of model, shock from one single macro economical factor can be transmitted by model and then impacts other factors,. Finally, ratio of NPL will be changed. Therefore, banking system could make use of lagged NPL to impose on macro economy.

One Advantage of this model comes from the logic that changes in macro factors and changes in NPL barely happen simultaneously, and we introduces a dummy variable to be a proxy of write-off NPL in Agriculture Bank of China; Additional advantage follows the idea that VAR model should be a better option to reflect the interaction of factors and should have the feedback effect of commercial bank on macro economy. Given the perspective over the future and the role of commercial bank in economy development, the model is a good fit to practice in China.

\subsection{Data}

Default rates termed as NPL in this analysis are drawn from CBRC's database of default rates. CBRC data covers from Q1 in year 2004 to Q4 in 2010. In addition, we collect data of macro factors over the same period from Rui Si's and Zhong Hong's databases.

\subsubsection{Dependent Variable}

Credit risk refers to the potential possibility that bank borrower or dealer fails to comply with the original contract. NPLis one of important indicators to evaluate status of portfolio in commercial bank. As NPL rate gets higher, bank takes higher risk to call in a loan. Therefore, NPL rate can reasonably represent the default risk of commercial bank.

\subsubsection{Independent Variable}

As China redefined NPL of commercial banks in year 2004, data of NPL is limited. In virtue of the low availability of data, we refer to the variable from international literatures. A prior test helps us to select following variables in Table 1 to represent the macro economy. 
Table 1. Definition of variable

\begin{tabular}{|c|c|c|}
\hline variable & Name & Description \\
\hline Real GDP Growth & GGDP & $\begin{array}{l}\text { It reflects economical level in a specified period and is } \\
\text { a basic indicator to reflect the health status of } \\
\text { economy. }\end{array}$ \\
\hline Customer Price Index & CPI & $\begin{array}{l}\text { It measures the fluctuation in the price level of } \\
\text { customer goods and services purchased by households } \\
\text { and play a core role in market activity and monetary } \\
\text { policy. }\end{array}$ \\
\hline House price index & PI & $\begin{array}{l}\text { Housing loan accounts for a large part in banking } \\
\text { loans and many loans require house to be mortgage. } \\
\text { The fluctuation of housing price affects NPL greatly. }\end{array}$ \\
\hline Nominal Monetary growth & GM2 & It reflects the present monetary policy in China \\
\hline Dummy Variable & $\mathrm{D}$ & $\begin{array}{l}\text { In terms of volatile national NPL over years, the whole } \\
\text { nation or each province's commercial NPL shows a } \\
\text { turning point. }\end{array}$ \\
\hline
\end{tabular}

\section{Empirical Result}

\subsection{Model Estimation}

\subsubsection{Data Preprocess}

Based on equation (1), we found out $Y_{t}$ as the proxy of NPL $L_{t}$ Results from Dickey-Fuller test prove that not all time series are as stable as those lagged on year. Johansen and Juselius' test for multivariate cointegration is used to disclose that cointegration makes sense towards the interdependency among variables and the relationship between variables and mediator.

\subsubsection{Empirical Research}

Based on equation (2), we associate all economical variables with the equation and make use of Eviews 6.0 to conduct multi-linear regression. After step-by-step regression and selection in terms of the goodness of fit, AIC, SC guidelines, Table 2 reports more reliable regression results. The results indicate that GGDP, CPI, PI, GM2, $\mathrm{Y}(-1), \mathrm{PI}(-1)$ and dummy variable $\mathrm{D}$ are significant.

Table 2. Multi-linear regression and vector autoregression results

\begin{tabular}{|c|c|c|c|c|c|}
\hline \multirow{2}{*}{$\begin{array}{l}\text { Dependent } \\
\text { variables }\end{array}$} & \multicolumn{5}{|c|}{ Independent Variables } \\
\hline & $\mathrm{Y}$ & GGDP & CPI & GM2 & PI \\
\hline Intercept & $-3.266220 *$ & 14.40576 & -17.6452 & $77.76263 * * *$ & 4.727057 \\
\hline GGDP & $0.069473 * * *$ & & & & \\
\hline CPI & $0.032249 * * *$ & & & & \\
\hline GM2 & $0.031535^{*}$ & & & & \\
\hline PI & $-0.040289 * * *$ & & & & \\
\hline $\operatorname{GGDP}(-1)$ & & $0.852448 * * *$ & $0.395101 * * *$ & $-0.48173 * * *$ & $0.554839 * * *$ \\
\hline CPI(-1) & & $-0.22641 * * *$ & $0.785986^{* * *}$ & & \\
\hline GM2(-1) & & & $0.339725 * * *$ & & $0.629976^{* * *}$ \\
\hline $\mathrm{PI}(-1)$ & $0.037683 * *$ & & $0.292577 * *$ & $-0.58382 * * *$ & $1.028439 * * *$ \\
\hline$Y(-1)$ & $0.551769 * * *$ & $-0.57868 * * *$ & $-0.76251 * * *$ & $2.099909 * * *$ & $-1.58407 * * *$ \\
\hline $\mathrm{D}$ & $0.844701 * * *$ & & & & \\
\hline R-squared & 0.994219 & 0.785658 & 0.824484 & 0.944714 & 0.890078 \\
\hline ADJ.R-squared & 0.99209 & 0.734624 & 0.782695 & 0.93155 & 0.863906 \\
\hline AIC & -2.003143 & 2.717686 & 3.290962 & 3.237944 & 3.5488 \\
\hline obs & 27 & 27 & 27 & 27 & 27 \\
\hline
\end{tabular}

Then, we take advantage of equation (3) to complete auto regression towards each dependent variable. Empirical 
results in table 2 show that variable lagged on year performs best and therefore we should build first-order VAR Later AR unit test is used to in the previous model . Since all 4 characteristic root lie inside unit circle, the VAR model is stable. And table 2 demonstrates that independent variables are lagged to certain degree. And we can see the independency among lagged variables. Moreover, all the macro economical variables are impacted by previous grouping component.

\subsection{Regression Analysis}

Table 2, elaborates that dummy variable D is significant (0.844701) in the model. In Q4, 2008, remarkable removal of NPL from balance of Agriculture Bank of China contributes greatly to reduction of NPL in national banking system. Four macro economical variables are significantly related to grouping component. And NPL is most sensitive to fluctuation of GGDP (0.069437). High GDP growth means the boom of national economy. In the bullish years, firm makes high profit and has better ability to make payment, which makes NPL decline. Movement of GM2 predicts changes in monetary policy. When central bank accelerates money supply, government is in favor of deregulation. Sufficient money supply lowers cost of finance, increase profitability and reduce non-performing loans. Loose monetary policy leads to inflation. The process could be seen from VAR model where lagged GM2 should take responsible for part of changes in CPI. Moderate rise in CPI indicates adequate money supply and is a good signal to NPL on the balance of commercial banks. PI and $\mathrm{Pi}_{\mathrm{t}-1}$ are negatively significant to $\mathrm{Y}_{\mathrm{t}}$. Rise in housing price lagged one year means that real estate market is in prosper, which indicates that captain chain in the market is in good status and solvency is strong. Due to the increasing price index, a large amount of funds are attracted into real estate market. Overcapitalized housing market takes risk of producing economic bubble, which enables more default. Therefore, our model is practically oriented.

\section{Simulation of Macro Shock and Analysis}

This paper applies sensitivity analysis and scenario analysis to stress testing. Given independent variables in the article, we set up two stress scenarios. Figure 1 depicts how NPL responds to fluctuation of risk factors in the first scenario. In order to accurately perceive the result, we assume that each risk factor will be changed by the same proportion. The second scenario stimulates the worst situation when all the extreme shocks happen in one year. We will analyze NPL in unanticipated tough time.

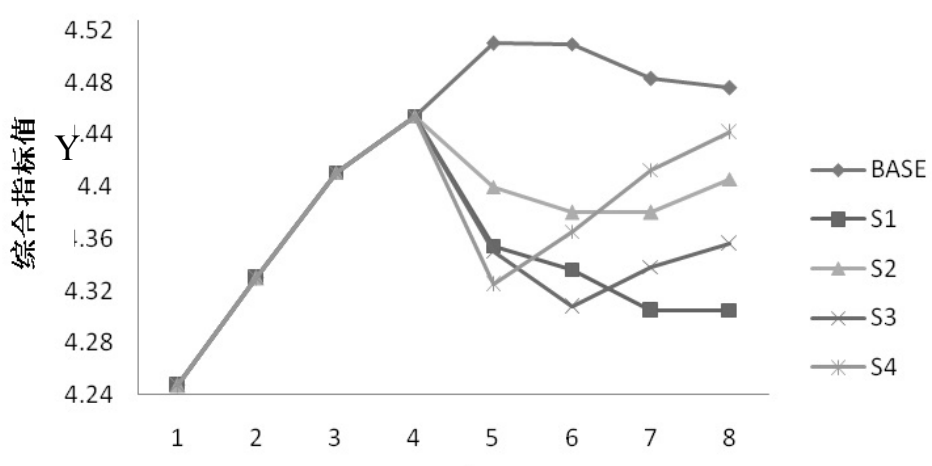

\subsection{Stressed Scenarios}

Figure 1. Scenario 1 stress testing graph

First scenario: Suppose growth rate of GDP, CPI and GM2 will be reduced by 3\% in Q1 2011 while PI will increase by $3 \%$, the new estimation should be 7.3\% (GDP), 100.3 (CPI), 17.8\% (GM2), 112.4 (PI), which are respectively reflected in Figure 1 termed S1, S2, S3 and S4.

Second scenario: Suppose there will be a fall in GDP by 3.1\% and CPI by 6.5\% in Q1 2011, which resembles Asian crisis over the period from Q4, 2008 to Q1 2009. Meanwhile, we retain the supple of monetary. Then, after GDP and CPI are reduced by the same proportion, we inject more money into market like what Chinese government decided in Asian crisis.

\subsection{Stress Test Result}

Based on VAR model, we look into the future and then obtain baseline scenario. First of all, we analyze predication in first scenario. The results show that grouping component will be lowered to a certain degree due to the poor performance of macro factors. And in our article grouping component is contrast with NPL. In a short 
time, NPL rate is more sensitive to changes in PI than to other macro factors. In Q1 2011, the movement of NPL experienced unimaginably drastic fluctuation, but the interaction among macro factors in model is able to smooth NPL curves and the turning point appears quickly. In a long time, movements of GDP and GM2 are the most volatile and have the longest influence.

Then, we start to analyze the scenario two. Table 3 gives more details about the result. In the "worst" scenario, we can see an obvious rise in NPL of Chinese commercial banks when there is downside in national economy and slump in CPI.. Comparison between $1^{\text {st }}$ scenario and $2^{\text {nd }}$ scenario leads to the discovery that QE (Quantitative Easing) program in economic depression generates more money supply and efficiently stops the increase in NPL. QE helped Chinese government survive in the last financial crisis. Therefore, in case of high CPI, Chinese government could decrease money supply moderately, which minimizes the negative influence on NPL of commercial bank and satisfies the requirement of monetary policy.

Table 3. Stress test results in scenario 2

\begin{tabular}{ccccccc}
\hline & \multicolumn{2}{c}{ baseline } & \multicolumn{2}{c}{ 1st scenario } & \multicolumn{2}{c}{ 2nd scenario } \\
\cline { 2 - 7 } & $\mathrm{Y}$ & $\mathrm{NPL}$ & $\mathrm{Y}$ & $\mathrm{NPL}$ & $\mathrm{Y}$ & NPL \\
\hline 2011q1 & 4.510099 & 0.010878 & 4.166432 & 0.015271 & 4.296774 & 0.01343 \\
2011q2 & 4.509237 & 0.010887 & 4.116071 & 0.016047 & 4.188899 & 0.014936 \\
$2011 \mathrm{q} 3$ & 4.482648 & 0.011177 & 4.12787 & 0.015862 & 4.194392 & 0.014856 \\
2011q4 & 4.475791 & 0.011253 & 4.195042 & 0.014846 & 4.270543 & 0.013782 \\
\hline
\end{tabular}

In 1st scenario, data from the end of 2010 indicates that accumulated amount of loans by 2010 in China reaches 31704.3 billion. Reserves against loan loss and depreciation are 795.943 billion. In depression, NPL peaks at $1.6047 \%$ and the dollar amount is 509.33659B. Obviously, in these two stressed scenario, bank system as a whole can depend on reserves to cover risk exposures. The assets are relatively safe.

\section{Conclusion}

This paper improves the stress-testing model prevailing globally. We use past demographic date of China to construct practically oriented macro stress-testing model. Initially, we take non-linear relationship between macro economical factors and default rates into consideration. Therefore, logit function is applied to find the proxy of NPL. Under the condition that Chinese government wrote off plenty of bad assets from the balance of ABC in Q4 2008, this paper introduces a dummy variable to represent the removal of NPL and enables a corresponding function. Finally, we make use of interaction between macro factors in VAR model to predict a baseline in the future. .

As for the selection of macro factors, we follow the idea from international and domestic model and reasonably choose GGDP, CPI, GM2 and PI as macro factors. And the selection takes into consideration the limitation like less transparency in economical data statistics and disclosure than western countries.

This paper specifies macro factors and NPL rate of commercial bank from Q1 2004 to Q4 2010 , totally 28 quarters, and then uses Eviews 6.0 software to analyze. Results show that dummy variable is significantly related to NPL rate with a comparatively higher coefficient, which means that NPL of national commercial bank as a whole extremely benefits from removal of NPL in ABC. If we got rid of the write-off NPL in our model, it is impossible to tell the influence of removal from that of macro shocks. At the same time, four macro factors have stong relationship with NPL rate. After we apply sensitivity analysis and scenario analysis to stress testing credit risk in national commercial banks, we observe that from short-term perspective, NPL is more sensitive to PI than to other three macro factors. Movement of NPL rate has quite winding path, but the interaction among macro factors in model framework is able to smooth NPL curves. In long term, GGDP and GM2 impacts NPL most and has longest-lasting influence. Based on the data from the end of year 2010, this paper simulates scenario that we experienced in 2008 financial crisis and suggests that when bearish happens and NPL surges, national reserves against loan loss and depreciation can resist to such shock. Meanwhile, in depression, loose monetary policy stimulates economy and efficiently prevent further increase in NPL in better economical environment.

\section{References}

Allan Kearns. (2004). Loan Losses and the Macro economy: A Framework for Stress Testing Credit Institutions' Financial Well-Bein. Financial Stability Report, 111-121.

Boss M. (2002). A Macroeconomic Credit Risk Model for Stress Testing the Austrian Credit Portfolio. Financial Stability Report, (4), 64-82. 
Merton R. (1974). On the Pricing of Corporate Debt :The Risk Structure of Interest Rates. Finance, 29(7), 449-470.

Sun Lianyou. (2007). Stress Testing of Commercial Bank. Guangxi Financial Research, (11), 19-22.

Virolainen, K. (2004). Macro Stress-Testing with a Macroeconomic Credit Risk Model for Finland. Bank of Finland Discussion Paper.

Wilson T C. (1997b). Portfolio Credit Risk II. Risk, 10(10), 56-61.

Wilson T. C. (1997a). Portfolio Credit Risk I. Risk, 9(10), 111-117.

Wong J., Choi K. F., \& Pak-Wing Fong. (2008). A Framework for Stress-Testing Banks' Credit Risk. The Journal of Risk Model Validation, (SPRING), 3-23.

Xu Mingdong, \& Liu Xiaoxing. (2008). Financial System Stability Assessment: International Comparison Based on Macro - Stress Testing. Studies of International Finance, (2). 